RAJETÓRIAS

E PERSPECTIVAS 


\section{SIMONI GUEDES: uma trajetória na Antropologia dos Esportes}

\section{SIMONI GUEDES: A Trajectory in Sports Anthropology}

\section{Luiz Fernando Rojo}

Professor do departamento de Antropologia e do Programa de Pós-Graduação em Antropologia (PPGA) na Universidade Federal Fluminense (UFF). Coordenador da área de Antropologia dos Esportes na International Union of Anthropological and Ethnological Sciences (IUAES), membro do grupo Deporte y Sociedad da CLACSO, coordenador do Núcleo de Estudos e Pesquisas sobre Esporte e Sociedade (NEPESS/UFF) e editor da revista Esporte e Sociedade. ID ORCID: https://orcid.org/OOoo0001-6624-7485.

\section{Resumo}

Neste artigo analiso a trajetória de Simoni Guedes e seu papel na constituição, institucionalização e internacionalização do subcampo da Antropologia dos Esportes no Brasil e na América Latina. Partindo da importância de sua dissertação de mestrado, que inaugurou os estudos sobre futebol no Brasil, percorrendo a criação dos grupos de trabalho sobre esportes nos principais eventos acadêmicos e a formação do mais antigo núcleo de pesquisa sobre esportes no país, abordo como esta trajetória articulou iniciativas individuais com a preocupação em consolidar coletivamente esta área recém-criada. Apontando o sucesso desta empreitada, finalizo indicando alguns dos principais legados que sua carreira nos deixou e os desenvolvimentos posteriores deste subcampo.

Palavras-chave: Simoni Guedes; trajetória; Antropologia dos Esportes; legado; subcampo.

\section{Abstract}

In this paper, I discuss the Simoni Guedes' trajectory and her role in the constitution, institutionalization, and internationalization of the Anthropology of Sports subfield in Brazil and Latin America. Departing from the importance of her Master thesis, which founded Brazilian soccer studies, going through the creation of sports work groups in the most important academic events, and the formation of the oldest investigation center about sports in the country, this paper focus on how her trajectory articulated individual initiatives with the worry into consolidate collectively this newly established area. Indicating the success of this endeavor, I finished highlighting some of the main legacies which her career gave us and the later development of this subfield.

Key-words: Simoni Guedes; trajectory; Anthropology of Sports; legacy; subfield.

\section{INTRODUÇÃO}

Durante a XIII Reunião de Antropologia do Mercosul, realizada em Porto Alegre em julho de 2019, a Mesa-Redonda "Esporte e Lazer como Di- 
reitos Humanos", na qual estava prevista a participação de Simoni Guedes, foi rapidamente transformada, após a notícia de seu inesperado falecimento, em um espaço no qual o legado que ela deixou para a Antropologia dos Esportes no Brasil e na América Latina foi debatido em forma de homenagem para quem, no dizer de Pablo Alabarces, foi a inventora deste campo de estudos em nosso continente.

Este novo formato da mesa-redonda, que contou com a participação de Lía Ferrero (Universidad de La Plata), Pablo Alabarces (Universidad de Buenos Aires), Verónica Moreira (Universidad de Buenos Aires), Carmen Rial (Universidade Federal de Santa Catarina), Mariane Pisani (Universidade Federal do Tocantins), além de minha própria participação, pela Universidade Federal Fluminense, mostra um pouco de sua importância na constituição e institucionalização da Antropologia dos Esportes, bem como da abrangência que este campo tomou a partir de seu impulso inaugural.

Neste artigo pretendo, a partir das falas das pessoas presentes nesta mesa, de uma série de mensagens recebidas de várias partes do mundo logo após a notícia de sua morte e, principalmente, através do compartilhamento dos últimos quinze anos de sua trajetória, primeiro como supervisora de meu pós-doutorado e, logo em seguida, como colega de departamento, enfatizar alguns aspectos de sua carreira. Entre estes, darei especial atenção ao seu esforço para que este campo se consolidasse para além de sua própria atuação individual, o que se materializou na construção de grupos de trabalho na Associação Brasileira de Antropologia e nas Reuniões de Antropologia do Mercosul, na participação decisiva que teve na formação do Núcleo de Estudos e Pesquisas em Esporte e Sociedade (NEPESS), na criação da revista Esporte e Sociedade e no estabelecimento de inúmeros convênios internacionais, que fortaleceram e diversificaram a Antropologia dos Esportes.

\section{SIMONI GUEDES: UMA INOVADORA}

Oliveira (2018) discute como a produção e inserção científicas das mulheres sofrem uma série de constrangimentos, muitos dos quais invisíveis ao senso comum. Desde a questão da maternidade, passando por barreiras 
relativas ao sexo para obtenção de aprovações em editais, ela aponta como vão se estabelecendo obstáculos que levam a uma progressiva diminuição da presença de mulheres à medida em que observamos o número de pessoas nas graduações, mestrados, doutorados, docentes universitários, bolsas de produtividade, até chegar a uma quantidade extremamente reduzida quando observamos as mulheres com bolsa de produtividade $1 \mathrm{~A}$ no CNPq.

Durante minha pesquisa de mestrado (Rojo, 2001) já havia identificado como esta distribuição entre os sexos, entretanto, é variável mesmo dentro de uma única área. Analisando o curso de Medicina de uma faculdade pública do estado do Rio de Janeiro, pude observar como o número de mulheres e homens era praticamente idêntico, quando se tratava da quantidade total de professores e professoras, mas extremamente diferenciado quando focava nas especialidades. Assim, a Pediatria e os departamentos laboratoriais apresentava uma marcada maioria de mulheres, enquanto Ortopedia e Cirurgia eram predominantemente constituídas por homens.

No caso específico da Antropologia brasileira, como na grande maioria das Ciências Humanas, já há muito tempo existe uma presença significativa de mulheres. Entretanto, desconheço se existe algum trabalho ou levantamento sobre a distribuição por sexo entre as diferentes áreas dentro de nosso campo de conhecimento, o que seria bastante interessante para pensar como determinados temas são marcados por gênero. O que cabe aqui ressaltar, no entanto, é o ineditismo que sua dissertação de mestrado (Guedes, 1977) representou, também em termos do recorte temático a partir de sua condição de mulher. Não por acaso, quando DaMatta resolve convidar jovens pesquisadores para publicar com ele a coletânea "Universo do Futebol" (1982), temos a presença de três homens e uma única mulher, a própria Simoni Guedes.

Porém, como ela mesma salientou por diversas vezes, embora esta questão de gênero tenha trazido alguns contratempos, principalmente na dificuldade de reconhecimento de sua expertise, fora do âmbito acadêmico, ela também foi, na maioria das vezes e paradoxalmente, positiva principalmente em relação ao trabalho de campo:

Não, eu descobri rapidamente que ser mulher era uma grande vantagem naquele contexto. Claro que tinha uma série de desvantagens, o tal do terceiro tempo, por exemplo, que me era vedado. Mas, ao 
mesmo tempo, com os operários, por exemplo, tinha uma inversão, porque você sabe que na etnografia trabalhamos com várias estratificações. Assim, de um lado, eu era uma mulher, de classe média, com posses; mas de outro, eles é que sabiam das coisas e eu não. Então, eles estavam me ensinando coisas. Então eles partiam do princípio que eu não sabia nada de futebol, o que seria natural, e aí eles podiam me explicar coisas, enfim, eu podia fazer perguntas bobas, que parecessem bobas para eles: "Como é que é o campeonato? Como é que é jogar aqui?". Então, tem uma série de vantagens ${ }^{1}$.

Para além desta dimensão do gênero, no entanto, outro aspecto ressalta ainda mais a ousadia que marcou a decisão pela escolha do futebol como objeto de análise para uma dissertação de mestrado. Simoni Guedes iniciou este mestrado em 1972. Para quem acompanha o mundo do futebol, não se trata apenas de toda a tentativa de apropriação do tricampeonato mundial conquistado pela seleção na Copa do Mundo de 1970, no México. Embalado por esta vitória, pela situação econômica, que ainda demoraria um pouco mais para sentir os impactos da crise que marcou a segunda metade da década de setenta e que foi um dos elementos para o declínio da ditadura civil-militar que governava o Brasil, bem como pela oportunidade da comemoração dos cento e cinquenta anos da proclamação da independência, o governo militar estimulou a realização, neste mesmo ano, da Taça Independência. Esta competição reuniu vinte equipes (entre selecionados nacionais e equipes continentais representando a África e a América Central) e foi disputada em doze cidades, cobrindo as cinco regiões geográficas do país, tendo ampla cobertura midiática.

É neste contexto, portanto, em que o futebol foi rotulado como sendo "o ópio do povo", em uma releitura nacional da expressão de Karl Marx (1993) sobre a religião e que foi, em diferentes formas, apropriada pelos setores críticos à ditadura, incluindo parte significativa dos cientistas sociais, que Simoni Guedes escolheu o futebol como seu tema de pesquisa. Foi também neste contexto, no entanto, que alguns anos antes de Roberto DaMatta legitimar academicamente este tema de pesquisa, explicitamente criticando esta for-

Entrevista para o Ludopédio. Disponível em: https://www.ludopedio.com.br/entrevistas/simoni-lahud-guedes-parte-2/. 
mulação, Guedes já trazia a voz não apenas de um operário, mas de um líder sindical que questionava esta associação:

O jogador brasileiro é o melhor do mundo. Depende só de querer jogar e ter um técnico. Uma boa direção técnica. O Brasil não pode perder competição nenhuma. Porque só assim nós somos compreendidos como nação. Nós somos conhecidos agora há pouco, depois do Brasil ser campeão do mundo. Nem o café fez o Brasil ser um país grande como ele é. Foi o futebol que fez o Brasil ser grande. É por isso que eu não sou totalmente contra o futebol. Eu sou contra é um homem ganhar milhões e um trabalhador de pedreira ganhar salário mínimo. Mas para o Brasil, o futebol é uma coisa grande, grandiosíssima. Ninguém melhor do que nós! Pronto, acabou. Não adianta que não é nunca! (Dirigente sindical, em Bangu, em entrevista concedida em 1975). (GUEDES, 1998, epígrafe).

Mas não foi apenas na decisão de realizar uma dissertação sobre um tema até então ainda não estudado pela Antropologia brasileira que Simoni Guedes foi inovadora. Afinal, muitas pessoas entre as quais me incluo, desenvolvem suas dissertações de mestrado ou teses de doutorado sobre temas que, posteriormente, não se tornam o centro ou, pelo menos, um dos centros de sua carreira profissional. Ao contrário, no entanto, embora tenha, por algum tempo, se dedicado quase exclusivamente à análise das classes trabalhadoras, outro de seus focos de interesse, Guedes foi inovadora também pela constituição e consolidação do campo da Antropologia dos Esportes no Brasil e, posteriormente, na América Latina.

\section{SIMONI GUEDES: UMA CONSTRUTORA}

Como indicado no item anterior, logo após a defesa de seu mestrado em 1977 ela se dedicou a outros temas, deixando a questão do futebol temporariamente como algo para a qual era apenas, ocasionalmente, convidada a falar em alguns eventos, muitos dos quais não acadêmicos ou em outras áreas de conhecimento. 
Assim, apesar da sua participação na coletânea organizada por DaMatta em 1982, que amplia a visibilidade e o reconhecimento deste campo na Antropologia brasileira, esta opção se refletiu em sua produção bibliográfica entre este texto e o ano de 1998. Uma pesquisa em seu currículo neste período de quinze anos vai encontrar poucas referências ao tema do futebol. Foram duas participações em eventos (Guedes 1995a, 1996) e dois artigos (Guedes 1993, 1995b).

O contraste com o que ocorre a partir do ano de 1998 é expressivo. Este é o marco do lançamento de "O Brasil no campo do futebol” (Guedes, 1998a), primeiro livro publicado pela autora sobre esta temática e é também o ano em que ela, durante um congresso de Sociologia do Trabalho em Buenos Aires, conhece a Pablo Alabarces em um encontro que irá influenciar fortemente a carreira de ambos. Se observarmos apenas o período de três anos a partir deste texto e novamente olharmos sua produção bibliográfica, encontraremos um capítulo de livro (Guedes, 2000a), dois artigos (Guedes 1998b, 2000b) e três apresentações em congresso (Guedes 2000c, 2000d, 2000e). É nesta última apresentação, na 22a Reunião Brasileira de Antropologia, realizada em Brasília, que quero me focar, como ponto de partida para um processo de institucionalização da Antropologia dos Esportes, inicialmente no Brasil e, logo em seguida, internacionalmente.

Em sintonia com sua retomada do tema do futebol, Simoni Guedes não apenas participou do primeiro grupo de trabalho que incluiu esta dimensão em uma reunião da Associação Brasileira de Antropologia, mas o coordenou em conjunto com Carmen Rial. Naquele momento o grupo ainda se chamava Futebol e Imagem, como uma tentativa de ampliação do escopo temático para romper com possíveis dificuldades de aprovação no programa do evento, como ela mesma reconheceu. Este grupo, já devidamente renomeado como Antropologia dos Esportes, reapareceu no ano seguinte durante a IV Reunião de Antropologia do Mercosul, agora em parceria com Pablo Alabarces em um dos primeiros frutos daquele benfazejo encontro de anos atrás. Aqui cabe salientar mais uma de suas facetas que contribuíram para a consolidação deste grupo na forma como ela se realizou. Simoni Guedes argumentava que o nome deveria continuar a se referenciar ao futebol, dada a centralidade deste esporte não apenas para a constituição da identidade nacional - uma 
das questões centrais de sua elaboração na área - mas no próprio âmbito esportivo brasileiro.

O ponto a observar é simples mas, a meu ver, decisivo para uma sociologia dos esportes no Brasil: se rigorosamente qualquer esporte pode produzir a identificação coletiva através das vitórias, apenas o futebol o faz permanentemente, nas vitórias e nas derrotas. Por isso, até aqui, o Brasil continua sendo o país do futebol (...). O futebol, no Brasil, tem cumprido papel preponderante neste processo, produzindo experiências coletivas que propiciam a vivência de uma 'comunidade moral de brasileiros'. Situando-se como veículo catalisador da brasilidade, quase todos os seus eventos são redimensionados, assumindo significados que, de modo algum, podem ser imediatamente deduzidos dos fatos do esporte em si. (Guedes, 1998, p. 41).

No entanto, desde 1998 Pablo Alabarces já coordenava o grupo de trabalho "Deporte y Sociedad" junto ao Conselho Latino-americano de Ciências Sociais (CLACSO). Em prol da unidade do grupo recém-criado e da importância da incorporação de colegas e experiências dos demais países da América Latina, Guedes abriu mão de sua proposta o que, posteriormente, admitiu ter sido o melhor caminho para a efetiva incorporação de outras modalidades em um único espaço acadêmico.

Este detalhe, que poderia passar desapercebido se situado fora de um contexto mais amplo, aparece aqui como um exemplo de uma de suas características mais marcantes. Simoni Guedes era uma entusiasta do empreendimento coletivo, da construção de estruturas que fossem capazes de superar os limites da ação de um único indivíduo, era alguém consciente de que seu legado teria que ser capaz de frutificar para além de sua própria ação individual. De certa forma, todas as homenagens que recebeu, entre as quais este artigo se insere, embora fossem momentos que a constrangeriam, avessa que era às homenagens a si mesma, deveriam estar, mesmo que inconscientemente, no seu roteiro de vida, já que confirmam que as sementes que ela plantou frutificaram e que seus projetos terão continuidade.

A continuidade destes projetos, entre os quais estes grupos de trabalho na ABA e na RAM, foi algo cotidianamente pensado. Desde o primeiro momento, ela estimulou que novas pessoas fossem assumindo tarefas de orga- 
nização destes grupos. Inicialmente trabalhando ao seu lado, pesquisadores como Arlei Damo, Luiz Henrique de Toledo e outros eram convidados a coordenarem estes trabalhos até, posteriormente passarem eles mesmos a ocuparem o lugar de coordenadores principais nas reuniões da ABA, liberando Simoni Guedes para um investimento maior na ampliação deste grupo para outros países, o que será analisado de forma mais detida no próximo ponto. Neste aspecto, a dimensão da amizade, que ela procurou sempre cultivar entre os participantes destes grupos de trabalho, precisa ser analisada para além de um mero aspecto circunstancial.

Giner foi uma das primeiras antropólogas a refletir sobre o conceito de amizade grupal: "Nas sociedades mais complexas, a amizade tende a ser descrita como uma relação diádica. Entretanto, junto a este tipo de relação coexistem outros modos de amizade que conceitualizaremos com o termo genérico de amizade grupal" (1995:55, grifo no original). Em minha dissertação de mestrado parti deste conceito para refletir sobre os impactos da formação de grupos de amigos na constituição de redes entre os estudantes de Medicina com os quais desenvolvi meu trabalho de campo (Rojo, 2001). Desde estas formulações teóricas, podemos pensar como as relações de amizade grupais fortalecem a coesão entre membros de um determinado grupo, criando uma série de compromissos não explícitos entre eles que ultrapassam as regras escritas das instituições nas quais se inserem.

Esta coesão foi algo marcante nos grupos criados por Simoni Guedes e é possível afirmar que também aqui encontrou uma parceria extremamente harmônica em Pablo Alabarces e o grupo que se desenvolvia na Argentina. A preocupação em reunir os membros do grupo nos bares e restaurantes de cada cidade que visitávamos, o cuidado com sutilmente afastar uma ou outra pessoa que se mostrasse potencialmente causadora de disrupções, cada aspecto que pudesse contribuir ou prejudicar a formação daquele grupo de amigos era merecedora de sua atenção. O efeito disso pode ser medido, entre outros caminhos, por uma breve conversa que tive com um colega há alguns anos. O crescimento da Antropologia dos Esportes havia nos colocado um dilema. Como dar conta, dentro do limite de apresentações por grupo de trabalho, de garantir a renovação, incorporando uma série de novas pessoas que enviavam seus resumos, sem excluir os "veteranos" que continuavam a desejar participar? A solução encontrada foi criar mais um grupo, de modo a 
duplicar o número de vagas e poder, ao mesmo tempo, aprofundar algumas questões temáticas específicas. Na conversa citada acima, no entanto, meu colega perguntou: "enfim vocês se dividiram?", entendendo que teria havido algum tipo de "racha" ou problema interno que tivesse levado a uma cisão, ao que eu respondi: "não, nós nos multiplicamos!".

Foi neste movimento que nossas trajetórias se fundiram. Nos conhecemos em 2003, durante a RAM de Florianópolis, apresentados por uma amiga em comum e voltamos a nos encontrar poucos meses depois, no elevador da UERJ onde eu estava fazendo meu doutorado sobre relações de amizade em uma comunidade naturista (Rojo, 2012). Conversamos rapidamente sobre um dos tópicos de um capítulo, no qual eu pretendia discutir as relações entre as práticas esportivas naquela comunidade e o ideal de amizade que seus componentes pretendiam vivenciar. Já naquele momento, dois anos depois de sua divergência com Alabarces, Simoni estava convencida da importância de ampliar o escopo de temas e questões para além do futebol e enxergou em meu trabalho uma possibilidade de incorporar um objeto completamente inexplorado até então pela Antropologia no Brasil. Mais do que isto, ela investiu pesadamente tanto para me consolidar no grupo de esportes quanto para ampliar a presença de pessoas voltadas para a pesquisa de outras modalidades esportivas no grupo que estava se consolidando. Somente algum tempo depois pude ter a dimensão exata do que representou a dádiva de um exemplar do "Universo do Futebol" com o qual me presenteou na RBA de Olinda em 2004 - uma citação de um de seus últimos artigos ajuda a entender:

O livro é muito bonito, pois foi realizado por uma editora de arte, estando entremeado de reproduções de pinturas alusivas ao futebol. Não deve ter circulado muito, por ser caro. Eu mesma só recebi um exemplar, embora, pela primeira e única vez na minha vida, tenha recebido algum dinheiro de direitos autorais, alguns meses depois. (Guedes, 2017a, p. 366).

Além disso, imediatamente após o encerramento do evento, ela me convidou para participar do Núcleo de Estudos e Pesquisas sobre Esporte e Sociedade (NEPESS), que ela havia ajudado a organizar poucos meses antes na Universidade Federal Fluminense (UFF). A partir do trabalho em conjunto 
realizado neste núcleo realizei, sob sua supervisão, meu pós-doutorado sobre relações de gênero no hipismo (Rojo, 2010).

A formação do NEPESS, o mais antigo núcleo sobre esporte em funcionamento no Brasil, representou mais um passo no processo de amadurecimento deste campo de estudos. Um núcleo de pesquisas possibilitava um espaço de formação de novos pesquisadores em uma perspectiva multidisciplinar, ao mesclar estudantes de graduação, mestrado e doutorado com professores em diferentes estágios da carreira de cursos como Antropologia, História, Educação Física e, mais recentemente, Letras, Pedagogia, Psicologia. Mais uma vez aqui, Simoni Guedes exercitava sua capacidade de transformar seu carisma - utilizado aqui em um sentido coloquial, distinto daquele definido por Weber (2009) - e sua liderança individual em um projeto coletivo. Assim, tão logo ela percebeu que as pessoas que haviam se incorporado ao núcleo eram capazes de dar continuidade a este projeto, ela se retirou da coordenação do mesmo, embora nunca tenha deixado de participar de suas atividades, principalmente no impulso para a criação da revista Esporte e Sociedade, vinculada ao NEPESS e na busca por uma inserção internacionalizada para o núcleo.

\section{SIMONI GUEDES NO BRASIL E NO MUNDO}

Como falado acima, o encontro com Pablo Alabarces foi extremamente impactante na retomada do desenvolvimento do tema do futebol na carreira de Simoni Guedes, principalmente no investimento em ampliar sua área de atuação para além das fronteiras nacionais. Uma vez mais, tive a oportunidade de acompanhar esta trajetória internacional praticamente desde o seu nascedouro.

Logo após a segunda ou terceira reunião do NEPESS de que participei, ela comentou sobre a realização de um seminário de estudos em Buenos Aires, em um projeto de início de um intercâmbio que ela estava articulando com Pablo Alabarces e me convidou para participar também. Lá, durante a rodada de apresentações individuais, tive uma calorosa recepção do colega Otávio Tavares, da Universidade Federal do Espírito Santo (UFES): "Enfim 
mais alguém para discutir esporte que não seja futebol!". Se produzia ali o embrião de muitos trabalhos coletivos, de livros, de grupos de trabalho, de participações em eventos e de muitas amizades entre pessoas do Brasil e da Argentina que, pouco a pouco, foram incorporando colombianos, mexicanos, uruguaias, chilenos e quem mais quisesse se somar.

Como em todas as demais iniciativas de Simoni Guedes, este seminário estava inserido em um projeto de longo prazo. Ele se articulou, por um lado, com a ampliação da participação de orientandos de Pablo Alabarces nos grupos de Antropologia dos Esportes não apenas nas Reuniões de Antropologia do Mercosul, mas também em muitas Reuniões Brasileiras de Antropologia, bem como na nossa participação em congressos organizados pelo Colégio de Graduados em Antropologia da Argentina e na ampliação da nossa atuação para a retomada das reuniões da Associação Latino-americana de Antropologia (ALA). Para além disso, também resultou na formalização de um convênio entre a Universidad de Buenos Aires e a Universidade Federal Fluminense, o qual propiciou, entre outras iniciativas, a realização de um pós-doutorado para Simoni Guedes na Argentina, na proliferação de artigos comparativos entre os países do chamado Cone Sul, na elaboração de coletâneas escritas em ambos os países e, ainda mais importante, para a consolidação e visibilização de um núcleo sólido de pesquisadores que atuasse como ponta de lança de um projeto de difusão deste campo de estudos por toda a América Latina.

Este projeto deu muitos frutos. Um deles foi a relação que se estabeleceu com a "Red de Investigadores sobre Deporte, Cultura Física, Ócio y Recreación", organizada pelos pesquisadores mexicanos José Samuel Martinez Lópes, César Frederico Macias e de Roger Magazine que ampliou o campo de pesquisas para além do tema específico do esporte, em um movimento que ainda está em curso. Assim, o que nasceu voltado exclusivamente para o futebol e se desenvolveu a partir de um olhar para todo o fenômeno esportivo, passou a incluir a questão da recreação, do jogo e do lazer.

Outro dos frutos importantes se deu no estreitamento das relações com a Colômbia, principalmente a partir do doutorado que David Quitián realizou na UFF, orientado por Simoni Guedes. Como sempre, ela foi capaz de transformar uma das muitas tarefas que todos nós, que estamos nos programas de pós-graduação, temos que realizar em um empreendimento coletivo de mão-dupla. Quitián se beneficiou de sua orientação, da inserção no NEPESS e do 
contato com uma extensa rede de pesquisadores brasileiros que, em maior ou menor grau, se articulou com o grupo multidisciplinar de estudos do esporte na Colômbia. Guedes, bem como todos nós, pôde por sua vez avançar em seu projeto de consolidar uma rede latino-americana que englobasse todas aquelas pessoas envolvidas com uma perspectiva das Ciências Sociais na análise do esporte e do lazer.

Por fim, a relação que se estabeleceu com o "Centro de Estudios Socioculturales del Deporte", coordenado por Rodrigo Lagos no Chile, embora menos aprofundada que as anteriores em termos de sua participação individual, foi uma das que propiciou a retomada de um dos primeiros projetos de unificação dos estudos do esporte no continente. O grupo CLACSO sobre Esporte e Sociedade, que Alabarces coordenava quando ele e Simoni Guedes se conheceram em 1998, foi dissolvido em 2002. Entretanto, por iniciativa de Lagos e de Verônica Moreira, uma das "filhas acadêmicas" de Pablo Alabarces e atualmente professora da Universidad de Buenos Aires, com o apoio de uma extensa rede de pesquisadores da América Latina e muitos de nós, "filhos acadêmicos" de Simoni Guedes, este grupo foi recriado tendo sido responsável por diversos encontros, publicações e um curso virtual sobre esportes.

Esta trajetória mostra que, além do comprometimento com a construção do campo dos estudos sociais do esporte, Simoni Guedes esteve fortemente conectada com o que, nos últimos anos, tem sido chamado de diálogo sul-sul. Entretanto, também em sintonia com a percepção de que sul, aqui, vai muito além de uma compreensão geográfica, adquirindo conotações políticas e acadêmicas, a centralidade de sua atuação na América Latina não a impediu de aproveitar o âmbito de convênios oriundos de outros campos de sua atuação profissional para ampliar esta rede para Portugal. Desta forma, tivemos um profícuo trabalho de diálogo com João Sedas que resultou em diversas participações em congressos brasileiros e portugueses e projetos conjuntos de investigação.

Duas questões merecem ser ainda desenvolvidas no encerramento deste item. A primeira é que todo este projeto de internacionalização esteve, permanentemente, vinculado a uma dimensão fundante da Antropologia, que é a importância do método comparativo, o qual Simoni Guedes demandou constantemente como uma necessidade a ser ainda consolidada no campo da Antropologia dos Esportes. 
Chamo a atenção para a importância destes projetos porque estabelecem uma plataforma de investigação comum que pode ser realizada de modo independente por cada pesquisador em seu país mas produzindo dados comparáveis. Este é um primeiro grande passo para a produção de um olhar latino-americano sobre os esportes, sobre o futebol antes dos outros. Devo advertir, no entanto, que, como sabemos, produzir dados comparáveis não é tudo. É necessário saber como comparar e, nessa direção, temos ainda muitos debates a realizar (...). Isto porque, a meu ver, só a comparação permite compreender toda a dimensão de significados de determinados fenômenos. Exemplifico com meu próprio trabalho de investigação, durante alguns anos, sobre projetos sociais esportivos no Brasil (...). Entretanto, só fui compreender a dimensão maior deste fenômeno brasileiro quando realizei pesquisa na Argentina sobre o mesmo tema. (GUEDES, 2017b, p. 14).

A segunda questão, que replica aqui a sua constante preocupação com a institucionalização de seus projetos, tais como abordei no ponto anterior, foi a forma como este processo de internacionalização foi ensinado para cada um de nós que nos formamos a partir de sua orientação. Assim, não posso deixar de citar que, mesmo não sendo diretamente parte de sua trajetória, a constituição da Comissão de Antropologia dos Esportes da International Union of Anthropological and Ethnological Sciences (IUAES), que comecei a elaborar a partir do Intercongresso de 2017, no Canadá e que foi formalizada no Congresso Mundial de 2018, no Brasil, faz parte desta trajetória que Simoni Guedes inaugurou e é diretamente devedora do legado que ela inspirou.

Cabe identificar que também a IUAES, embora seja uma associação mundial, se forjou a partir das iniciativas oriundas de antropólogos e antropólogas que buscavam uma alternativa de organização global que partia do já referido diálogo sul-sul. Neste sentido, nossa comissão dos esportes se insere no mesmo processo iniciado por Simoni Guedes e Pablo Alabarces, tanto na direção de conformar uma Antropologia dos Esportes em escala planetária, integrando a contribuição latino-americana no diálogo com os demais continentes, quanto no sentido de ampliar as possibilidades comparativas para uma dimensão global. 


\section{CONCLUSÃO}

Neste artigo sobre a trajetória de Simoni Guedes falei extensamente sobre sua importância para a construção do campo da Antropologia dos Esportes. Deixei propositalmente, dada a característica de um trabalho que é, simultaneamente, uma homenagem a sua carreira e ao legado que a fez ser reconhecida por todos os seus pares como a nossa "matriarca", a discussão teórica sobre o conceito de campo (Bourdieu, 2004) para a conclusão, de modo a salientar, no conjunto desta apresentação, sua contribuição para a criação de uma nova área de estudos na Antropologia.

Antes de mais nada, portanto, deve-se precisar que, conceitualmente falando, deveríamos nos referir ao subcampo da Antropologia dos Esportes, ainda que este não possa ser pensado como uma "parte" de um campo mais amplo da Antropologia, como o próprio Bourdieu sinalizou em uma de suas muitas entrevistas:

[...] um campo não tem partes, componentes, cada subcampo tem sua própria lógica, suas regras e regularidades específicas e cada etapa na divisão de um campo implica em um verdadeiro salto qualitativa (como, por exemplo, quanto se passa de um nível do campo literário em seu conjunto ao subcampo da novela ou do teatro). (Bourdieu, 2005, p. 159).

Feita esta correção teórica, podemos retomar o fluxo da trajetória de Simoni Guedes dentro do "campo científico" (Bourdieu, 2004) no qual, como o próprio autor salienta, há uma pressão particular sobre as pessoas que estão no processo de admissão a este e que consiste particularmente na "sublimação dos interesse externos, políticos" (ib: 30) ao campo.

Sublimação que, tacitamente, exigida de todo recém-chegado, é implicada nesta forma particular de illusio inerente ao pertencimento a um campo, isto é, a crença científica como interesse desinteressado e interesse pelo desinteresse, que leva a admitir, como se diz, que o jogo científico merece ser jogado, que ele vale a pena, e que define os objetos dignos de interesse, interessantes, importantes, capazes, portanto, de merecer o investimento. (ib:30). 
Assim é que sua singularidade se expressou, desde o início de sua caminhada, ao romper com esta lógica da escolha pelos objetos já canônicos e, mais do que isso, em buscar o futebol como tema de pesquisa, desafiando justamente os interesses externos que, no período político em que inicia seu mestrado, atuavam em contraposição à autonomia do campo científico.

No entanto, mesmo esta ruptura, como foi mostrado no início deste trabalho, não prescindiu da legitimação posterior dada por uma pessoa situada no campo da Antropologia e dotada de "capital simbólico" suficiente para organizar um "rito de instituição" capaz de transformar aquele objeto em algo digno de interesse, como foi o caso da coletânea organizada por Roberto DaMatta. Além disso, através de um intenso processo de organização deste subcampo da Antropologia dos Esportes e de um investimento teórico e metodológico na qualificação da produção - própria e de seus orientandos e orientandas - a própria Simoni Guedes foi capaz de contribuir fortemente para o reconhecimento da área:

O reconhecimento, marcado e garantido socialmente por todo um conjunto de sinais específicos de consagração que os pares-concorrentes concedem a cada um de seus membros, é função do valor distintivo de seus produtos e da originalidade (no sentido da teoria da informação) que se reconhece coletivamente à contribuição que ele traz aos recursos científicos já acumulados. (BOURDIEU, 1983, p. 132).

Se, como o próprio autor indica, este reconhecimento também se materializa em termos de prêmios e outras formas de honrarias que os próprios pares outorgam, a legitimação do subcampo da Antropologia dos Esportes foi ampliada com os trabalhos de Arlei Damo, ganhador da melhor tese da área de Antropologia e Arqueologia, no Prêmio Capes e melhor tese de doutorado do concurso ANPOCS, ambos em 2006.

Esta, no meu entendimento, é a melhor forma de terminar este artigo. A trajetória de Simoni Guedes não se encerrou sequer com sua morte. Ela continua no legado que deixou a cada um de nós que trabalhamos e construímos a Antropologia dos Esportes e que dá sentido às belas palavras que meu irmão dedicou a ela: 
"Pessoas que vivem da ciência, como nós e a Simoni, também acreditamos na imortalidade, não do ponto de vista da genética, mas porque somos ideias, pensamentos, ensinamentos. Enquanto houver gente capaz de transmitir nossas ideias e ensinamentos, as pessoas não morrem. Assim, apesar de compreender a tua tristeza, enquanto fores capaz de continuar a transmitir o legado da Simoni, ela continuará viva, em ti e em todas as pessoas que por ela foram tocadas. É uma grande responsabilidade que passam a ter, a de manter Simoni imortal."

\section{REFERÊNCIAS}

1. BOURDIEU, Pierre. El Proposito de la Sociología reflexiva. In: BOURDIEU, Pierre; WACQUANT, Loïc. Una invitación a la sociología reflexiva. Buenos Aires: Siglo XXI Editores Argentina, 2005. p. 147-173.

2. BOURDIEU, Pierre. O Campo Científico. In: Renato Ortiz (org.). Pierre Bourdieu - Sociologia. São Paulo: Editora Ática, 1983. p. 122-155.

3. BOURDIEU, Pierre. Os usos sociais da ciência: por uma sociologia clínica do campo científico. São Paulo: UNESP, 2004.

4. DAMATTA, Roberto. Universo do Futebol: esporte e sociedade brasileira. Rio de Janeiro: Pinakotheke, 1982.

5. GINER, Josepa Cucó. La amistad: perspectiva antropológica. Barcelona: Icaria, 1995.

6. GUEDES, Simoni. A Construção do corpo masculino nas escolinhas de futebol. In: XX ENCONTRO ANPOCS, Caxambu, 1996.

7. GUEDES, Simoni. As duas vidas dos craques: o sucesso e os limites dos poderes

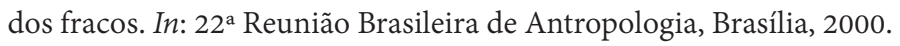

8. GUEDES, Simoni. Entrevista concedida a Ludopédio. 22 maio 2013. Disponível em: https://www.ludopedio.com.br/entrevistas/simoni-lahud-guedes-parte-2/. Acesso em 12 de ago. 2019.

9. GUEDES, Simoni. Malandros, caxias e estrangeiros no futebol: de heróis e anti-heróis. In: GOMES, Laura Graziela; BARBOSA, Lívia; DRUMMOND, Jose Augusto (Org.). O Brasil não é para principiantes: Carnavais, malandros e heróis, 20 anos depois. 1. ed. Rio de Janeiro: Fundação Getúlio Vargas, 2000a. 
10. GUEDES, Simoni. O Brasil no campo de futebol: estudos antropológicos sobre os significados do futebol brasileiro. Niterói: Eduff, 1998a.

11. GUEDES, Simoni. O Futebol Brasileiro: instituição zero. Dissertação (Mestrado em Antropologia) - Museu Nacional, UFRJ, 1977.

12. GUEDES, Simoni. O povo brasileiro no campo de futebol. À Margem - Revista de Ciências Humanas, Rio de Janeiro, v. 1, n.3, p. 5-15, 1993.

13. GUEDES, Simoni. O povo brasileiro no campo de futebol. Revista DF Letras, Brasília - DF, v. 54-56, p. 14-19, 1998 b.

14. GUEDES, Simoni. O salvador da pátria: considerações em torno da imagem do jogador Romário na Copa do Mundo de 1994. Pesquisa de Campo, Rio de Janeiro, n.1, p. 23-41, 1995b.

15. GUEDES, Simoni. Os trabalhadores e o futebol no Rio de Janeiro. In: XV REUNIÃO DA SBPH, Rio de Janeiro, 1995a.

16. GUEDES, Simoni. Prólogo: redescobrindo a América. In: LAGOS, Rodrigo Soto; VERGARA, Omar Fernandéz (Orgs.). ¿Quién raya la cancha? Visiones, tensiones y nuevas perspectivas en los Estudios Socioculturales del Deporte en Latinoamérica. Buenos Aires: CLACSO, 2017b.

17. GUEDES, Simoni. Que povo brasileiro no campo de futebol?. In: VI Congresso Luso-Afro-Brasileiro de Ciências Sociais, Porto - Portugal, 2000d.

18. GUEDES, Simoni. Resenha de Archetti, Eduardo. 1999. Masculinities: Football, polo and the tango in Argentina.. Mana, Rio de Janeiro, v. 6, n.1, p. 175-178, 2000b.

19. GUEDES, Simoni. Sobre permanências e transformações em contextos acadêmico-institucionais: um relato pessoal. Revista Antropolítica, n. 42, Niterói, p.339-373, 1. sem. 2017a.

20. GUEDES, Simoni. Tempo da nação: as Copas do Mundo como rituais nacionais brasileiros. In: IX Simpósio Regional da ANPUH-RJ, Niterói, 2000c.

21. MARX, Karl. Manuscritos econômico-filosóficos. Lisboa: Edições 70, 1993.

22. OLIVEIRA, Letícia. Mulheres na ciência: forças invisíveis que influenciam a representatividade feminina. Palestra na CAPES, 2018.

23. ROJO, Luiz Fernando. Borrando los sexos, creando los géneros: construcción de identidades de género en los deportes ecuestres en Montevideo y Rio de Janeiro. Vibrant, Florianópolis, v.6, p.50-71, 2010. 
24. ROJO, Luiz Fernando. Os diversos tons do branco: relações de amizade entre estudantes de Medicina. Rio de Janeiro: Litteris, 2001.

25. ROJO, Luiz Fernando. "Vivendo 'nu' paraíso": comunidade, corpo e amizade na Colina do Sol. Rio de Janeiro: Dígrafo, 2012.

26. WEBER, Max. Economia e Sociedade: fundamentos da sociologia compreensiva. Brasília: EdUnB, 2009. 